Article

\title{
Effects of $\mathrm{N}_{2}$ Partial Pressure on Growth, Structure, and Optical Properties of GaN Nanorods Deposited by Liquid-Target Reactive Magnetron Sputter Epitaxy
}

\author{
Muhammad Junaid, Ching-Lien Hsiao * (D), Yen-Ting Chen ${ }^{(1)}$, Jun Lu, Justinas Palisaitis, \\ Per Ola Åke Persson, Lars Hultman and Jens Birch * (D) \\ Thin Film Physics Division, Department of Physics, Chemistry, and Biology (IFM), Linköping University, \\ SE-581 83 Linköping, Sweden; Muhammad.Junaid@husqvarnagroup.com (M.J.); \\ james_hokkeko@yahoo.com.tw (Y.-T.C.); junlu@ifm.liu.se (J.L.); juspa@ifm.liu.se (J.P.); \\ per.persson@liu.se (P.O.Å.P.); larhu@ifm.liu.se (L.H.) \\ * Correspondence: ching-lien.hsiao@liu.se (C.-L.H.); jbh@ifm.liu.se (J.B.); Tel.: +46-13-28-12-28
}

Received: 6 February 2018; Accepted: 30 March 2018; Published: 7 April 2018

\begin{abstract}
GaN nanorods, essentially free from crystal defects and exhibiting very sharp band-edge luminescence, have been grown by reactive direct-current magnetron sputter epitaxy onto Si (111) substrates at a low working pressure of 5 mTorr. Upon diluting the reactive $\mathrm{N}_{2}$ working gas with a small amount of $\operatorname{Ar}(0.5$ mTorr), we observed an increase in the nanorod aspect ratio from 8 to $\sim 35$, a decrease in the average diameter from 74 to $35 \mathrm{~nm}$, and a two-fold increase in nanorod density. With further dilution ( $\mathrm{Ar}=2.5 \mathrm{mTorr}$ ), the aspect ratio decreased to 14 , while the diameter increased to $60 \mathrm{~nm}$ and the nanorod density increased to a maximum of $2.4 \times 10^{9} \mathrm{~cm}^{-2}$. Yet, lower $\mathrm{N}_{2}$ partial pressures eventually led to the growth of continuous GaN films. The observed morphological dependence on $\mathrm{N}_{2}$ partial pressure is explained by a change from $\mathrm{N}$-rich to Ga-rich growth conditions, combined with reduced GaN-poisoning of the Ga-target as the $\mathrm{N}_{2}$ gas pressure is reduced. Nanorods grown at 2.5 mTorr $\mathrm{N}_{2}$ partial pressure exhibited a high intensity $4 \mathrm{~K}$ photoluminescence neutral donor bound exciton transitions $\left(\mathrm{D}^{0} \mathrm{X}_{\mathrm{A}}\right)$ peak at $\sim 3.479 \mathrm{eV}$ with a full-width-at-half-maximum of $1.7 \mathrm{meV}$. High-resolution transmission electron microscopy corroborated the excellent crystalline quality of the nanorods.
\end{abstract}

Keywords: GaN; nanorods; X-ray diffraction; TEM; photoluminescence; magnetron sputter epitaxy; sputtering

\section{Introduction}

Low-dimensional semiconductor nanostructures, such as nanorods (NR), have drawn an interest due to their great prospects in novel nanotechnology applications as well as in fundamental material physics, i.e., understanding the growth mechanisms of nanostructures, effects of different surface energies on the adatom mobility, etc. These are promising components for future applications in nano-electronics and nano-optoelectronics [1-4]. GaN, with a direct wide band gap of $3.4 \mathrm{eV}$ and a high electron mobility is a promising material and is being exploited in these kinds of devices. Catalyst-free GaN-NR growth has successfully been demonstrated by chemical vapor deposition (CVD), hydride vapor phase epitaxy (HVPE) [5-7], physical vapor deposition (PVD) (i.e., molecular beam epitaxy (MBE) [8-11]) and direct-current magnetron sputter epitaxy (DC-MSE) [12-15]. Magnetron sputter deposition is a well-established method which can easily be up-scaled to grow over very large areas for industrial applications. In addition, it provides for low-energy ion assisted deposition which can be used to lower the growth temperature. DC-MSE is a promising method as it employs ultra-high 
vacuum (UHV) conditions and ultra-high-purity source materials, thus combining the advantages of magnetron sputter deposition and those of MBE. DC-MSE has also been demonstrated for the growth of high quality GaN continuous epilayers [16,17] as well as NRs. Besides the mass and energy of incident reactive species, selective control of metal-ion fluxes, substrate bias synchronized to probe gas-ion or metal-ion irradiation, is available in a more controlled manner with more complicated sputtering configurations being employed, such as high-power impulse magnetron sputtering (HiPIMS), hybrid HiPMS/DC-MSE co-sputtering using synchronized pulsed substrate bias, MSE with applying external magnetic field, etc. [18-21]. These methods have been applied to achieve single-phase multi-nary alloys grown at low temperature, which demonstrates a high capability to use MSE for the material growth of high-performance optoelectronics.

DC-MSE of GaN-NRs/Si (111) has been reported, using a pure $\mathrm{N}_{2}$ environment, with a total pressure varying from 5 to 20 mTorr. The NRs exhibited excellent optical properties with band-edge (BE) emission at $3.477 \mathrm{eV}$ with a full-width-at-half-maximum (FWHM) value of $1.7 \mathrm{meV}$ when grown at the highest $\mathrm{N}_{2}$ partial pressure value of 20 mTorr. This coincided with the best achieved structural quality, highest aspect ratio, and highest growth rate of the NRs.

However, working at high pressures of pure $\mathrm{N}_{2}$ with DC-MSE, such as 20 mTorr, poses several challenges. For example, it is difficult to maintain a stable process at such pressures when sputtering in a $\mathrm{N}_{2}$-rich environment. Sputtering a metallic Ga target under such conditions results in the formation of a GaN compound of low electrical conductivity on the surface, so called target poisoning, which is a major issue. Target poisoning is known to strongly limit the achievable deposition rate and, in some cases, inhibit sputtering altogether. Moreover, after the growth of GaN-NRs using a pure nitrogen environment, target poisoning effects make it impossible to grow continuous GaN epilayers, which require an $\mathrm{Ar} / \mathrm{N}_{2}$ mixture, using the same nitrided target. Another disadvantage of using high working pressures, like 15 or 20 mTorr, is that throttling of the UHV pumping system often is required in order to maintain a stable pressure. Such practice reduces the pumping speed and thus, effectively eliminates the UHV conditions during growth, which increases the probability of impurity incorporation into the growing material. A high process pressure also leads to gas scattering of the sputtered Ga which, in turn, leads to a lower degree of utilization of the source material and unwanted deposition of Ga remote from the substrate. It is thus desirable to lower the total pressure and reduce the amount of $\mathrm{N}_{2}$ in the sputtering gas for DC-MSE GaN-NRs growth.

In this work, we have investigated the effect of a low $\mathrm{N}_{2}$ partial pressure in $\mathrm{Ar} / \mathrm{N}_{2}$ mixture (5 mTorr), compatible with GaN epilayer growth, to achieve high quality GaN-NR growth onto Si substrates at $1000{ }^{\circ} \mathrm{C}$ by using the DC-MSE growth process. The dependence of the structural and the optical properties on $\mathrm{N}_{2}$ partial pressure is discussed, taking into account the changing growth modes combined with a reduced poisoning effect of the Ga-target. The as-grown nanorods are characterized by scanning electron microscopy (SEM), cross-sectional high-resolution transmission electron microscopy (HRTEM), X-ray diffraction (XRD), and micro-photoluminescence ( $\mu$-PL) spectroscopy.

\section{Materials and Methods}

The GaN nanorods were grown by home-made reactive DC-MSE for 120 min on Si(111) substrates kept at a temperature of $1000{ }^{\circ} \mathrm{C}$. A very careful temperature calibration was performed to measure the exact surface temperatures on the substrate, and Minolta Land Cyclops infrared-pyrometers (Ametek Land, Dronfield, United Kingdom) were also used as an extra measurement tool during the calibration process. During growth, we also checked the surface temperature from time to time to reconfirm the surface temperature.

Liquid Ga (99.99999\%), contained in a horizontal stainless-steel tray of $50 \mathrm{~mm}$ diameter, was used as a magnetron sputtering target with a constant magnetron power of $10 \mathrm{~W}$. The sputtering was carried out in a reactive environment using $\mathrm{N}_{2}$ (99.999999\%) and Ar (99.999999\%) as working gases. The high-purity of gas (99.999999\%) was achieved by using $99.9999 \%$ gas, further purified by special gas purifiers. The depositions were performed in a homemade UHV-chamber, without any cooling shroud, 
with a base pressure of $\sim 5 \times 10^{-9}$ Torr. The partial pressures of $\mathrm{N}_{2}\left(P_{\mathrm{N} 2}\right)$ and $\mathrm{Ar}\left(P_{\mathrm{Ar}}\right)$ varied from $P_{\mathrm{N} 2}$ $=5 \mathrm{~m}$ Torr and $P_{\mathrm{Ar}}=0 \mathrm{~m}$ Torr to $P_{\mathrm{N} 2}=1 \mathrm{mTorr}$ and $P_{\mathrm{Ar}}=4 \mathrm{mTorr}$, keeping the total pressure constant at 5 mTorr for all depositions. For convenience, we will most often refer only to the $P_{\mathrm{N} 2}$ values in this article, while $P_{\mathrm{Ar}}+P_{\mathrm{N} 2}$ always equals 5 mTorr. During growth, no substrate rotation was used.

The Si (111) substrates were cleaned in ultrasonic baths of trichloroethylene, acetone, and 2-propanol for $5 \mathrm{~min}$ at each step and were blown dry with $\mathrm{N}_{2}$ just prior to inserting them into the chamber via a load-lock system.

A Zeiss-Leo 1550 field emission SEM (Zeiss, Oberkochen, Germany), operated at $10 \mathrm{kV}$, was used to study the surface morphology and to measure the length, diameter, and areal number density of the nanorods from side- and plan-view micrographs of the samples. Growth rate was determined by using the average length of the nanorods, measured by SEM cross-sectional micrograph, and dividing it by the total growth time. The average rod density was determined using topographical and cross-sectional micrograph by SEM and calculating the number of rods in certain area.

The microstructures of the as-deposited GaN nanorods were investigated by cross-sectional HRTEM using a FEI Tecnai G2 TF 20 UT field-emission TEM (Thermo Fisher Scientific, Eindhoven, Nederland), operated at $200 \mathrm{kV}$. The cross-sectional TEM samples were prepared by mechanical polishing, followed by Ar ion milling at $5 \mathrm{keV}$. Final polishing was done using low energy ions at $2 \mathrm{keV}$.

To characterize the crystal structure, overview $\theta-2 \theta$ XRD scans were performed with a Philips 1820 Bragg-Brentano diffractometer (Malvern, Almelo, The Netherlands). A Phillips X'Pert MRD diffractometer (Malvern, Almelo, The Netherlands), using $\mathrm{Cu} \mathrm{K} \alpha$ radiation, with a four-axis goniometer, and configured with $1 \times 1 \mathrm{~mm}^{2}$ crossed slits as the primary optics and a $0.27^{\circ}$ parallel plate collimator as secondary optics was used for pole-figure measurements. Pole-figure measurements were performed for the GaN (1015)-plane spacing with a fixed $2 \theta$ angle of $\sim 105.3^{\circ}$.

Optical properties were characterized by $\mu$-PL (homemade) at $4 \mathrm{~K}$ in a backscattering geometry. A continuous-wave (CW) Coherent Verdi/MBD-266 laser system $\left(\lambda_{\mathrm{exc}}=266 \mathrm{~nm}\right)$ was used as the excitation source. The setup details can be found in ref. [22].

\section{Results and Discussion}

Figure 1a-j show side- and plan-view SEM images of a sample with self-assembled GaN nanorods grown onto Si (111) substrates at different $P_{\mathrm{N} 2}$ and $P_{\mathrm{Ar}}$, with a constant total pressure at $5 \mathrm{mTorr}$. Figure $1 \mathrm{a}, \mathrm{b}$ present the cross-sectional and top-view morphologies of the rods grown in a pure nitrogen atmosphere $\left(P_{\mathrm{N} 2}=5 \mathrm{~m}\right.$ Torr $)$. The cross-sectional image shows that the nanorods have a uniform length of $\sim 550 \mathrm{~nm}$ and an average diameter of $\sim 74 \mathrm{~nm}$. The top-view morphology image shows that the rods exhibit highly irregular cross-sections. Figure 1c,d show the cross-section and top-view of the NRs grown at $P_{\mathrm{N} 2}=4.5$ mTorr, respectively. This reveals that exchanging a small amount of $\mathrm{N}_{2}$ to $\mathrm{Ar}\left(P_{\mathrm{Ar}}=\right.$ $0.5 \mathrm{mTorr}$ ) has a dramatic effect on the length and diameter of the rods. The average diameter of the rods shrinks to $\sim 34 \mathrm{~nm}$, and the average length increases to $\sim 1260 \mathrm{~nm}$. The rods are now well-separated without any coalescence, as shown in Figure 1d. Further dilution of the $\mathrm{N}_{2}$ working gas with Ar causes the rods to shrink in length, with average values of $1190 \mathrm{~nm}$ and $820 \mathrm{~nm}$ for $P_{\mathrm{N} 2}=3.5$ and $2.5 \mathrm{mTorr}$, respectively (see Figure 1e,g), while the average diameter increases to $36 \mathrm{~nm}$ and $60 \mathrm{~nm}$ for $P_{\mathrm{N} 2}=$ 3.5 and 2.5 mTorr, respectively. For the $P_{\mathrm{N} 2}$ of 2.5 mTorr, the bases of some of the rods are slightly broader with a shoulder, after which the rods become narrower in diameter, similar to what frequently has been observed in MBE grown GaN-NRs on $\operatorname{Si}(111)[23,24]$. The average diameter of the base is $\sim 80 \mathrm{~nm}$, and the top part is $\sim 40 \mathrm{~nm}$. Decreasing the $\mathrm{P}_{\mathrm{N} 2}$ beyond $2.5 \mathrm{mTorr}$ leads to the formation of a continuous, $245 \mathrm{~nm}$ thick, GaN film with large columnar grains with an average width of $100 \mathrm{~nm}$, instead of forming well separated NRs, as seen in Figure 1i,j.

The dependence of $\mathrm{N}_{2}$ partial pressure versus the growth rate and aspect ratio for the GaN-NRs extracted from Figure 1 is represented in Figure 2a. Upon introducing a small amount of Ar $\left(P_{\mathrm{N} 2}=4.5 \mathrm{~m}\right.$ Torr and $\left.P_{\mathrm{Ar}}=0.5 \mathrm{mTorr}\right)$ into the working gas, the GaN NRs growth rate is increased by a factor of two to $1.8 \AA / \mathrm{s}$, and the aspect ratio increases from 8 to $\sim 35$ compared to the pure $\mathrm{N}_{2}$ case. 
Morphologically, these NRs are very similar to the GaN-NRs grown at 20 mTorr partial pressure in a pure $\mathrm{N}_{2}$ environment. By further diluting the $\mathrm{N}_{2}$ gas to a $P_{\mathrm{N} 2}$ of $2.5 \mathrm{mTorr}$, the growth rate and aspect ratio continuously decrease to $1.1 \AA$ /s and $\sim 14$, respectively.
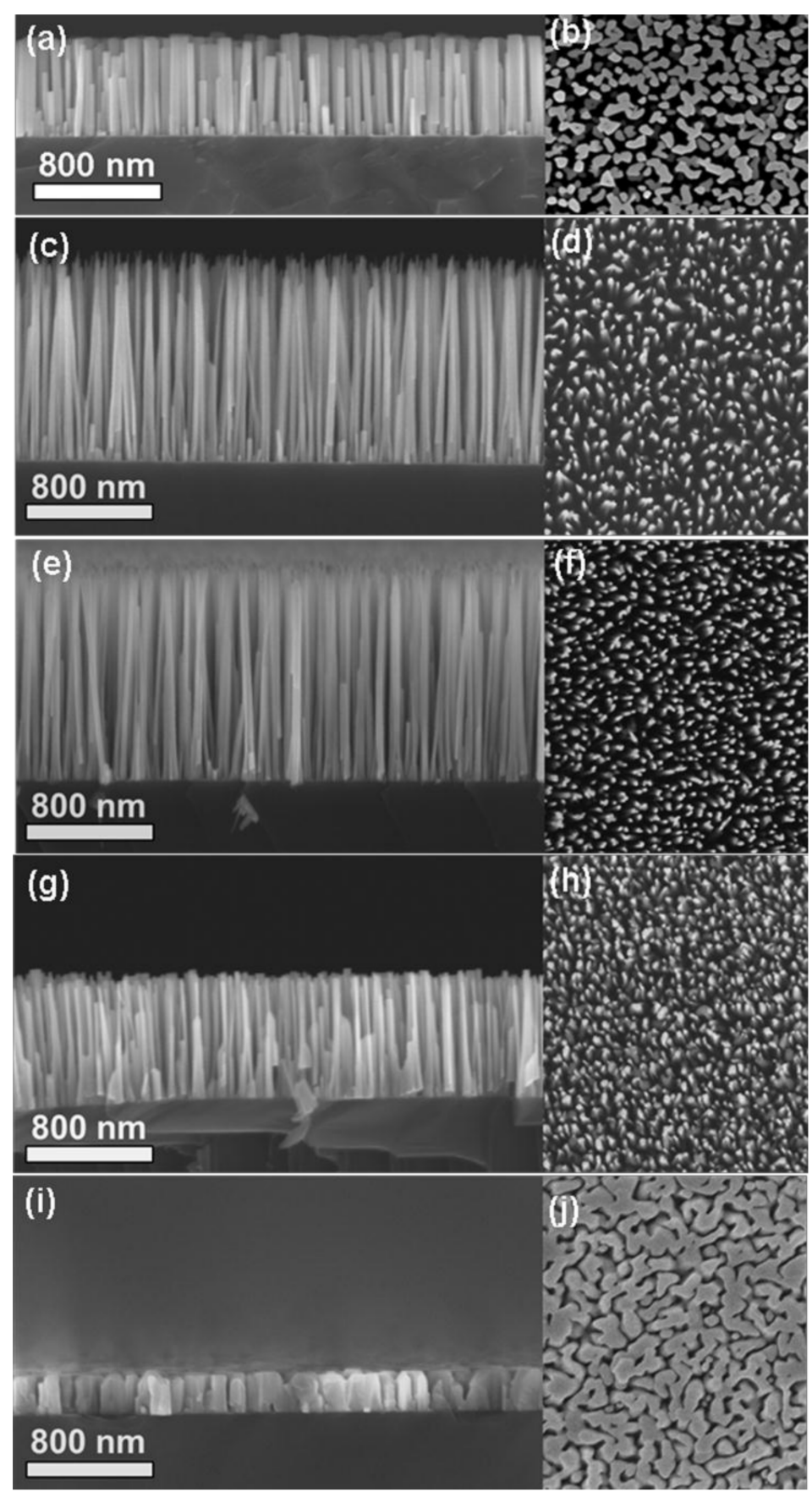

Figure 1. SEM micrographs showing side views (left) and top views (right) from GaN nanorod samples grown at $(\mathbf{a}, \mathbf{b}) P_{\mathrm{N} 2}=5$ mTorr; $(\mathbf{c}, \mathbf{d}) P_{\mathrm{N} 2}=4.5$ mTorr; $(\mathbf{e}, \mathbf{f}) P_{\mathrm{N} 2}=3.5$ mTorr; $(\mathbf{g}, \mathbf{h}) P_{\mathrm{N} 2}=2.5$ mTorr; $(\mathbf{i}, \mathbf{j}) P_{\mathrm{N} 2}$ $=1 \mathrm{mTorr}$ pressure on $\mathrm{Si}(111)$ substrates.

The estimated density of the nanorods presented in Figure $2 b$ shows that the rod density increases as $\mathrm{Ar}$ is introduced into the sputtering gas. The highest density is obtained at $P_{\mathrm{N} 2}=2.5$ mTorr, whereafter, the density drops again. 
We suggest the following model to explain the observed changes in the evolution of the NR morphology as the gas composition is changed: When sputtering in a pure $\mathrm{N}_{2}$ environment, the Ga-target assumes a poisoned state, which reduces the sputtering yield of Ga. Moreover, the pure $\mathrm{N}_{2}$ atmosphere means that GaN nucleation occurs in a $\mathrm{N}_{2}$-rich regime. Such conditions are known to severely limit the Ga adatom mobility [25-30] and lead to small GaN nuclei which determines the diameter of the GaN nanorods, as also commonly seen in self-induced GaN NRs grown under nitrogen-rich conditions by plasma-assisted MBE [30-32]. These nuclei are formed with a lower verticality along the $c$-axis orientation of the $\mathrm{Si}$ substrate with a native amorphous $\mathrm{SiO} x$ during incubation, which has been observed in selective-area growth cases [14,15]. After the nuclei are formed, vertical growth of GaN nanorods can be explained on the basis of the so-called surface diffusion induced growth mechanism, which elucidates the effect of Ga adatom diffusion on the base, apex, and side walls of the nanorods as well as the incoming flux effect. During this MSE growth, the incoming flux is normally incident to the substrate, which minimizes the shadowing effect and fosters the growth along the flux direction. Since the growth along the $c$ axis is faster than other orientations and can be further enhanced by surface diffusion at higher growth temperatures, the verticality of the NRs becomes higher after the nucleation stage. This model has successfully described the growth of GaN nanorods in MSE, which is very similar to MBE-grown GaN NRs.
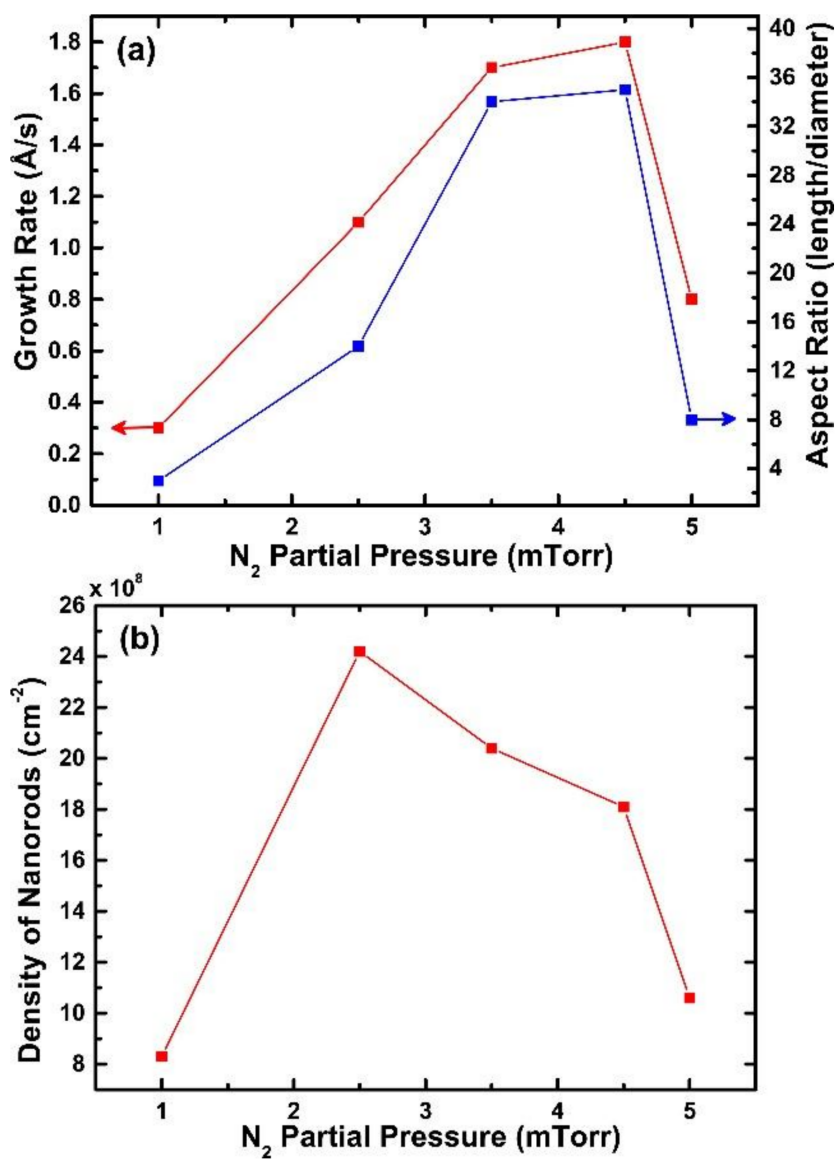

Figure 2. (a) Growth rate and aspect ratio and (b) variation of density of rods with nitrogen partial pressure, where $\mathrm{N}_{2}$ partial pressures varying from 5 to 1 mTorr.

By introducing Ar into the working gas, the Ga sputter yield increases, both due to better momentum transfer from the sputter gas (because of the larger mass of Ar) and also due to reduced target poisoning $[33,34]$. Thus, by increasing the $P_{\text {Ar }}$ to $0.5 \mathrm{mTorr}$, the Ga flux will increase compared to the case of pure $\mathrm{N}_{2}$. At the same time, the amount of the $\mathrm{N}$ available at the substrate surface for 
GaN formation will not be changed significantly because of the overall high $\mathrm{N}$ super saturation (N-rich conditions), such that the Ga limited adatom mobility condition prevails [25,31,32,35]. This will lead to a higher nucleation density (i.e., smaller nuclei), which, in turn, leads to an increased density of narrower and longer NRs, as is observed in our data. The continued increase in NR density as $P_{\mathrm{N} 2}$ is decreased to 2.5 mTorr shows that the nucleation in this pressure range essentially occurs in a N-rich regime (where the Ga adatom mobility is low) with an increasing Ga-flux. However, at the same time, the reduced aspect ratio and growth rate observed upon further dilution of the $\mathrm{N}_{2}$ sputter gas show that the conditions are changed such that the surface diffusion induced growth mechanism is less favored. This is an indication that the growth conditions are changing to less N-rich conditions, which increases the possibility of forming bigger GaN nuclei and the base of mature NRs, as reflected by a reduction in the aspect ratio and density of NRs (see Figure 2). At some point, upon further dilution of the $\mathrm{N}_{2}$ gas, the target surface will change from being GaN-poisoned to metallic, which will lead to a strong increase in the Ga flux towards the substrate, possibly leading to a fast transition into $\mathrm{N}$-deficient conditions. At the high growth temperature of $1000{ }^{\circ} \mathrm{C}$, the desorption rate of Ga adatoms from the substrate will increase if the availability of $\mathrm{N}_{2}$ becomes limited. Thus, the amount of Ga on the substrate will decrease at the same time as the Ga adatom diffusion length increases, which leads to a lower nucleation density and growth of larger grains at a low growth rate. Based on the observed transition from NR growth to the formation of a continuous GaN film (made up by large grains, see Figure 1i) at a low growth rate, when going to $P_{\mathrm{N} 2}=1 \mathrm{mTorr}$, we propose that target poisoning ceases and the growth changes to $\mathrm{N}$-deficient conditions at an $\mathrm{N}_{2}$ pressure between 1 mTorr and $2.5 \mathrm{mTorr}$. Thus, we conclude that the morphology of DC MSE grown GaN-NRs is qualitatively influenced by the $\mathrm{Ga}$ and $\mathrm{N}$ fluxes in a similar way as MBE-grown GaN NRs [25,31,32].

Long range $\mathrm{XRD} \theta / 2 \theta$ measurements were performed for the samples grown at different partial pressures and all the measurements were similar, showing only GaN 0002 and 0004 reflections along with the Si substrate peak. An example is shown in Figure 3, which shows an XRD $\theta / 2 \theta$ scan from the sample grown at $P_{\mathrm{N} 2}=4.5$ mTorr. Thus, the XRD results show that all GaN-NRs are oriented relative to the $c$-axis along the growth direction. To determine the in-plane orientation of the GaN nanorods, pole figures were recorded from all samples. A representative $\{10 \overline{15}\}$ pole figure (from $P_{\mathrm{N} 2}$ $=4.5 \mathrm{~m}$ Torr sample) is shown in Figure 4 . Similar results were observed from all samples. The pole figure reveals a high intensity ring at $\psi \sim 20^{\circ}$, corresponding to an azimuthally random orientation of the $\{101 \overline{5}\}$ planes, i.e., the nanorods are oriented with the $c$-axis along the growth direction with a random in-plane orientation. In Figure 4 three reflections are also visible at $\psi \sim 35^{\circ}$, separated by $\sim 120^{\circ}$ in $\varphi$, which correspond to the three-fold symmetry of the $\{440\}$ planes of (111)-oriented Si.

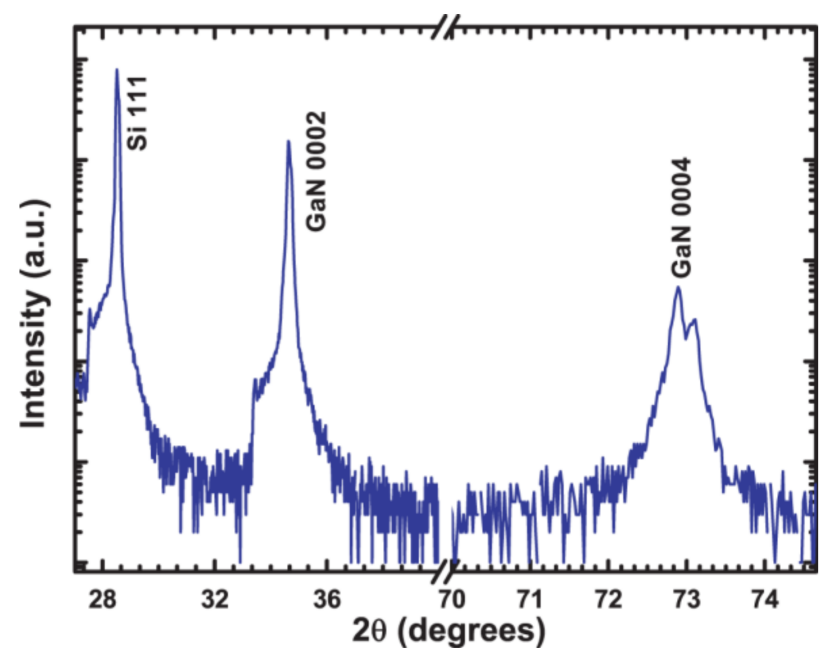

Figure 3. $\mathrm{XRD} \theta / 2 \theta$ scans from the sample grown at $P_{\mathrm{N} 2}=4.5$ mTorr. 
Low-temperature $\mu$-PL spectra characterizing the optical properties of the GaN-NRs are shown in Figure 5a. In the spectra, peaks from GaN have been identified as the free A exciton recombination $\left(\mathrm{X}_{\mathrm{A}}\right)$ and neutral donor bound exciton transitions $\left(\mathrm{D}^{0} \mathrm{X}_{\mathrm{A}}\right)$ [36], also known as the band-edge $(\mathrm{BE})$ luminescence. For the samples grown at $P_{\mathrm{N} 2}=5,4.5,3.5,2.5$ and $1 \mathrm{mTorr}$, the $\mathrm{D}^{0} \mathrm{X}_{\mathrm{A}}$ peak is visible at $\sim 3.477,3.481,3.478,3.479$, and $3.473 \mathrm{eV}$, respectively. For the $P_{\mathrm{N} 2}=3.5 \mathrm{mTorr}$ and $2.5 \mathrm{mTorr}$ samples, the $\mathrm{X}_{\mathrm{A}}$ peak is also well separated and visible at 3.484 and $3.485 \mathrm{eV}$, respectively. The corresponding FWHMs of the $\mathrm{D}^{0} \mathrm{X}_{\mathrm{A}}$ peaks are shown in Figure $5 \mathrm{~b}$. It can be seen that an exceptionally narrow emission line of only $1.7 \mathrm{meV}$ width is produced by the NRs grown at $P_{\mathrm{N} 2}=2.5 \mathrm{mTorr}$. The narrow BE luminescence from the GaN-NRs is attributed to high crystalline quality and low impurity incorporation. In fact, the NRs grown at $P_{\mathrm{N} 2}=2.5 \mathrm{mTorr}$ show very similar optical properties as those previously demonstrated by the MBE-grown GaN NRs and by DC-MSE-grown GaN NRs grown in a pure $\mathrm{N}_{2}$ atmosphere at 20 mTorr. Those NRs were shown to be almost entirely free from structural defects. The peaks visible at $\sim 3.429 \mathrm{eV}$ for all the NRs grown in this study at different partial pressures of $\mathrm{Ar}$ and $\mathrm{N}_{2}$ are attributed to basal plane stacking faults (SFs) as reported in ref. [37-39]. In addition, we also observed very broad yellow luminescence (YL) centered at around $2.35 \mathrm{eV}$ (not shown here). The peak is referred to the structural defect and/impurity incorporation in GaN [40-42]. The peak intensity of $\mathrm{YL}$ is four times weaker than the $\mathrm{D}^{0} \mathrm{XA}$ emissions in all samples and has a similar trend of stacking-fault emissions with varying partial pressure. Hence, it is more relevant to the generation of structural defect (plasma-induced defects) in the NRs. However, impurity incorporation through diffusion into structural defects, either during growth or after sample's exposure to air, cannot be ruled out completely. Such defect-related peaks were not observed in the spectra from the DC-MSE GaN nanorods grown at a working pressure of 20 mTorr in a pure $\mathrm{N}_{2}$ atmosphere [12]. However, at lower pressures, such as in the present work, the plasma surface interaction increases significantly due to the increased mean free path in the plasma, which increases the local heat, so that crystal damage, caused by the energetic species impinging on the surface of the growing crystal, may occur.

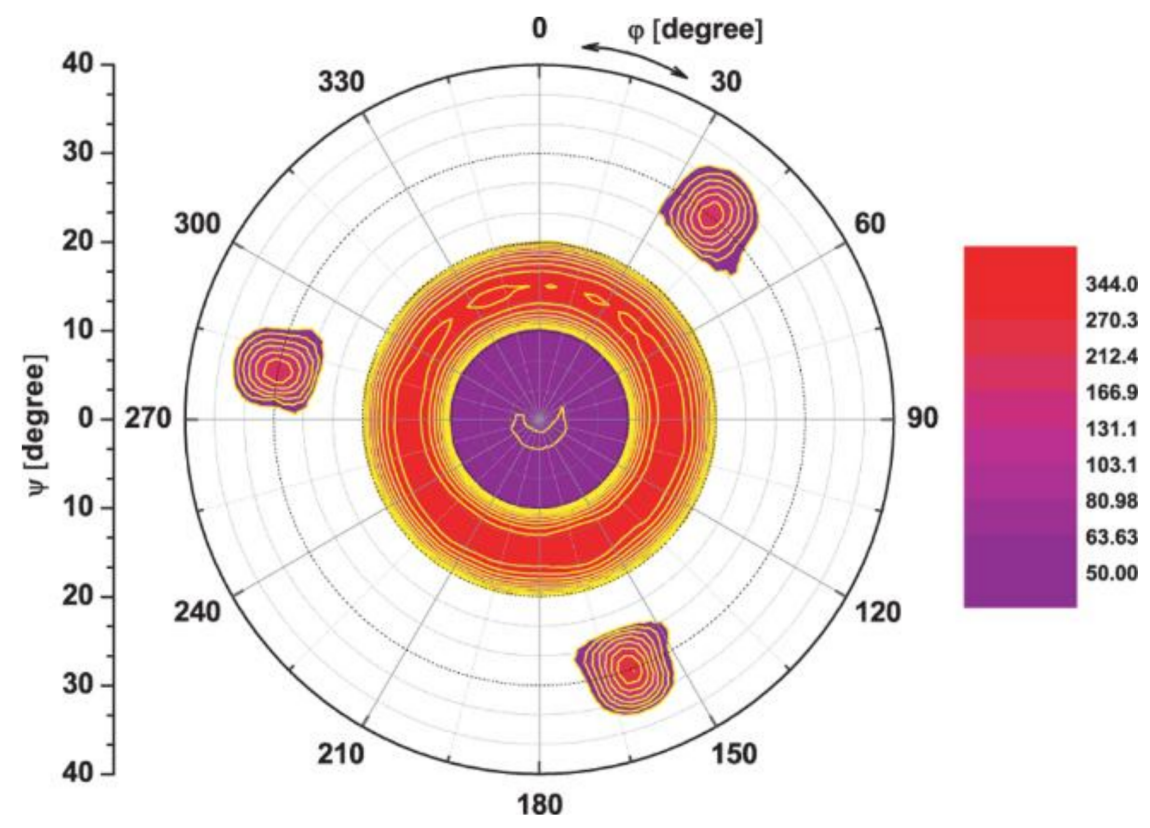

Figure 4. $10 \overline{15}$ Pole-figure measurements of GaN nanorods grown at $P_{\mathrm{N} 2}=4.5$ mTorr.

In order to study the structural quality of GaN-NRs, HRTEM was performed. For these studies, the two samples grown at $P_{\mathrm{N} 2}=4.5$ mTorr and $P_{\mathrm{N} 2}=2.5$ mTorr which demonstrated the highest aspect ratio and best optical properties, respectively, were selected. Figures 6 and 7 show lattice resolved images from the interface, middle, and top part of the NRs grown at $P_{\mathrm{N} 2}=4.5$ mTorr and $P_{\mathrm{N} 2}=$ 
2.5 mTorr, respectively. The HRTEM results showed that nucleation starts on the thin amorphous native oxide layer present on the $\mathrm{Si}$ (111) substrate surface for both $P_{\mathrm{N} 2}=4.5 \mathrm{mTorr}$ and $P_{\mathrm{N} 2}=2.5 \mathrm{mTorr}$ and that NRs have a random in-plane orientation, which is in agreement with the XRD texture results. The random in-plane orientation was expected, due to the amorphous surface oxide which lacks substrate lattice registry between the NRs and substrate. In both samples, the rods exhibit a high crystal quality from bottom to top. A few isolated stacking faults are seen randomly distributed along the growth direction in the $P_{\mathrm{N} 2}=4.5$ mTorr sample, and the number of stacking faults is higher in this sample compared to the 2.5 mTorr sample in Figure 7 , which exhibits no observed stacking faults. This corroborates the conclusion from the PL data that the $P_{\mathrm{N} 2}=2.5$ mTorr sample is of exceptionally high structural quality. The observed stacking faults in Figure 6 may be related to the process dependent luminescence peak, visible at $3.429 \mathrm{eV}$ in the $4 \mathrm{~K} \mu$-PL spectra of Figure 5.
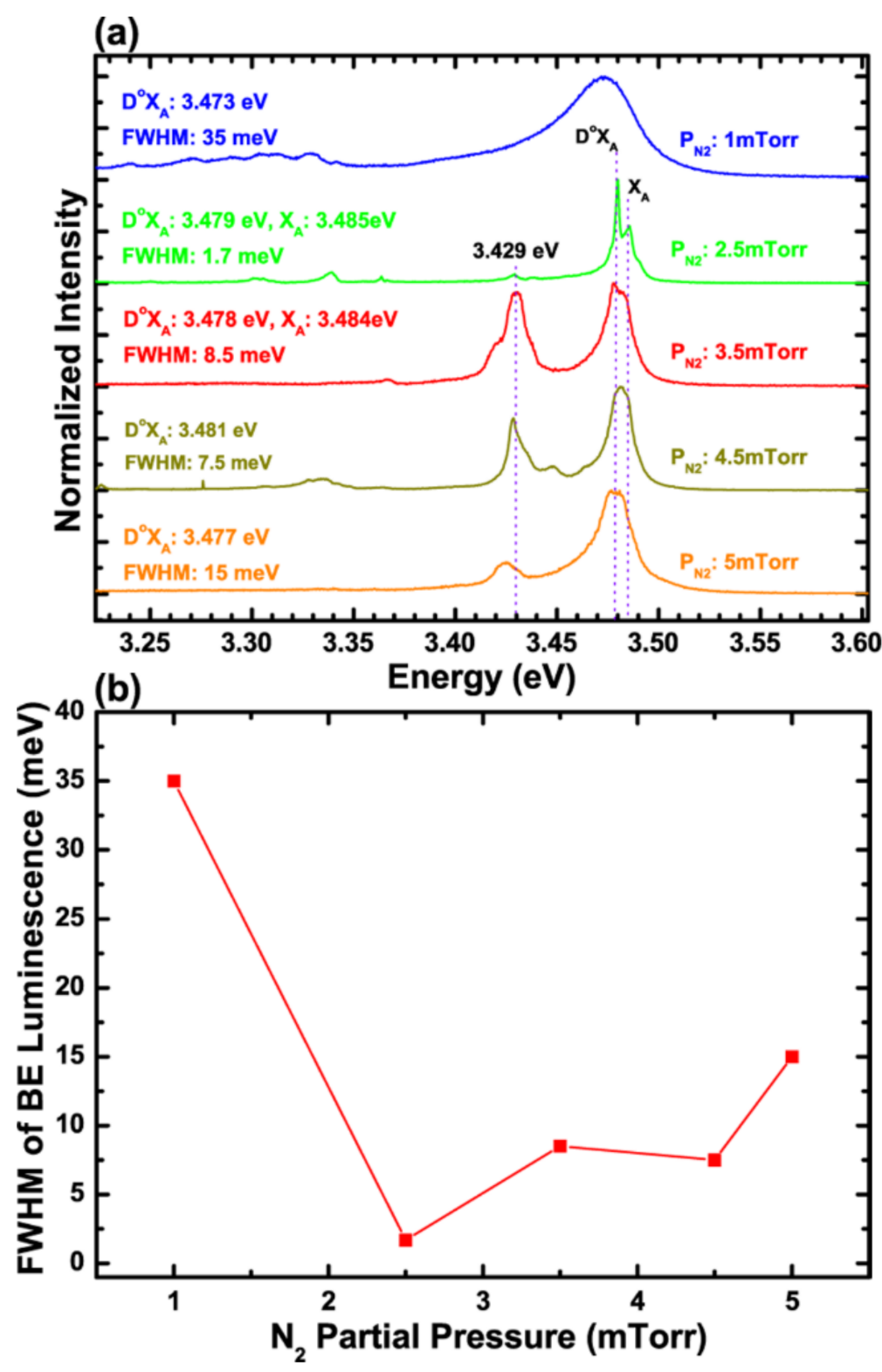

Figure 5. (a) $\mu$-PL Spectra from GaN nanorods grown at different nitrogen partial pressures and (b) full-width-at-half-maximum (FWHM) of band-edge luminescence vs. nitrogen partial pressure. 


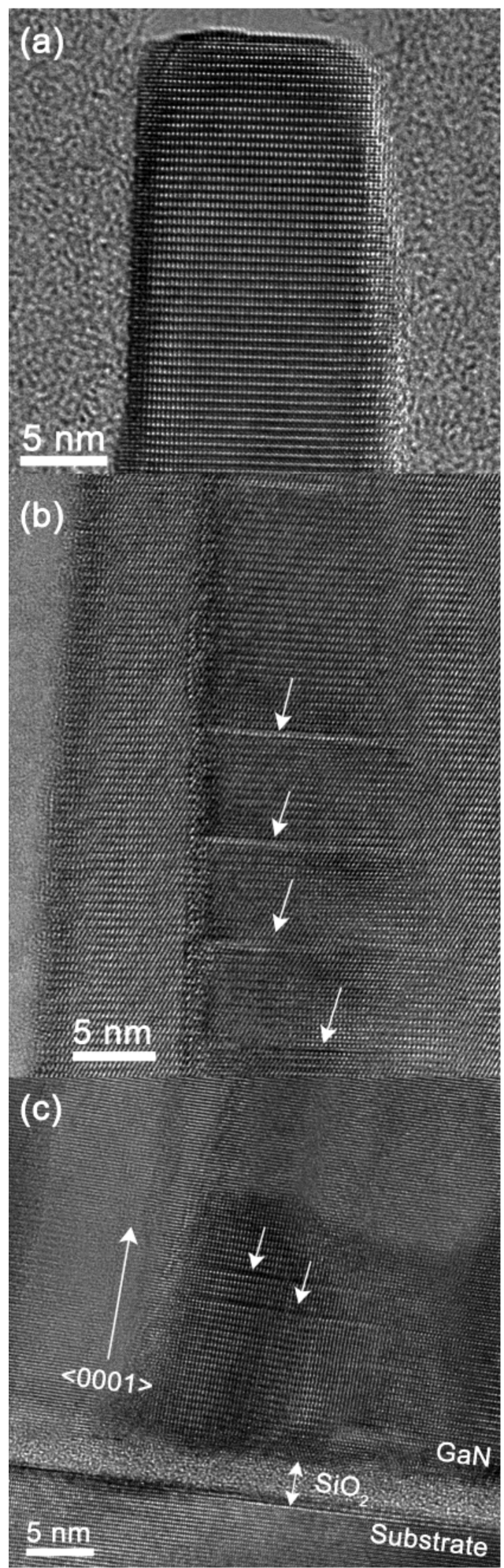

Figure 6. Cross-sectional HRTEM images from a GaN nanorod grown at $P_{\mathrm{N} 2}=4.5$ mTorr on $\mathrm{Si}(111)$ substrate showing (a) the top part of the nanorod; (b) the middle part of the nanorod with stacking faults indicated by the arrows; and (c) the interface between the substrate and nanorods, containing the native oxide layer at the interface. Stacking faults close to the interface are indicated by arrows. 


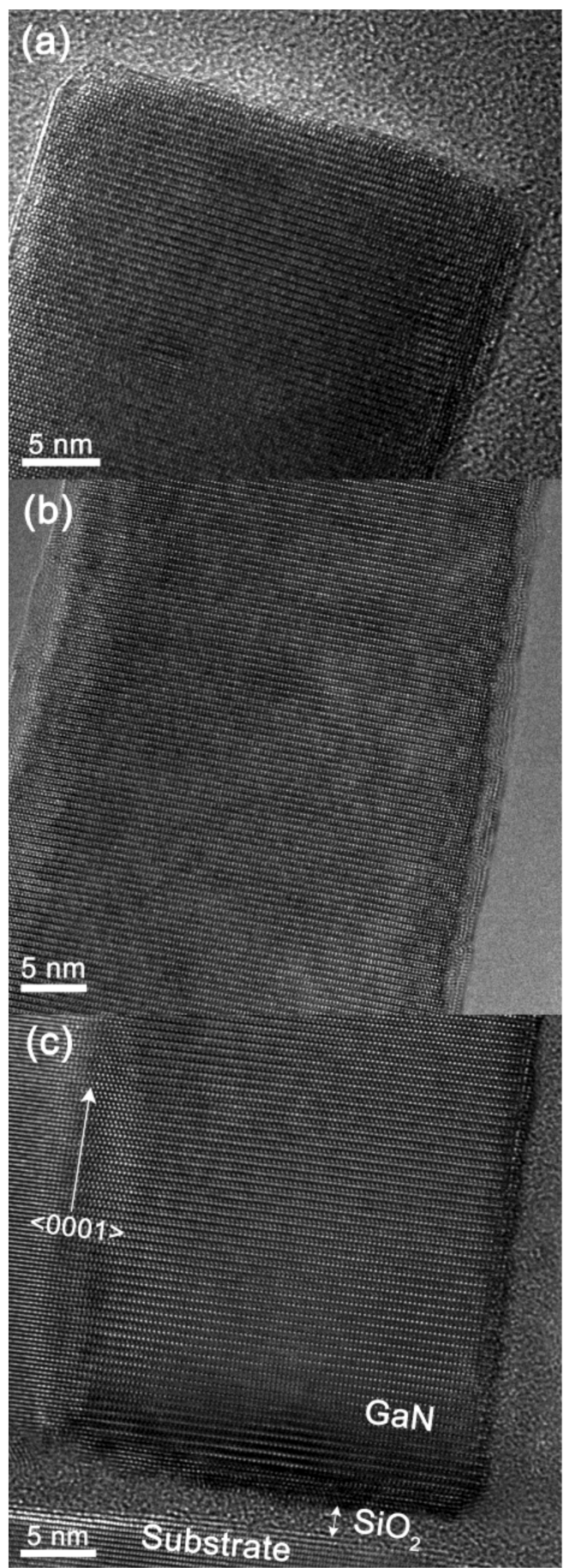

Figure 7. Cross-sectional HRTEM images from the GaN nanorod grown at $P_{\mathrm{N} 2}=2.5 \mathrm{mTorr}$ on $\mathrm{Si}(111)$ substrate showing (a) the top part of the nanorod; (b) the middle part of the nanorod; and (c) the interface between the substrate and nanorods, containing the native oxide layer at the interface.

\section{Conclusions}

By diluting the reactive $\mathrm{N}_{2}$ working gas with Ar in DC-MSE, single-crystal wurtzite GaN nanorods, grown onto $\mathrm{Si}(111)$ at a low total pressure of $5 \mathrm{mTorr}$, were achieved. This total working pressure is four times less than previously reported for growth in pure $\mathrm{N}_{2}$ environment, which will allow for better purity of the as-grown nanorods thanks to a lower probability of contamination from the residual gas partial pressure. The growth kinetics, structure quality, and optical properties of $\mathrm{GaN}$ are 
highly dependent on the ratio of $\mathrm{Ar} / \mathrm{N}_{2}$. A process window in terms of Ar partial pressures was found, ranging from $P_{\mathrm{Ar}}=0.5 \mathrm{mTorr}$ to $2.5 \mathrm{mTorr}$, where GaN nanorods were formed. The highest aspect ratio of nanorods was achieved for $P_{\mathrm{Ar}}=0.5 \mathrm{mTorr}$ while the best optical properties were achieved at $P_{\mathrm{Ar}}=2.5 \mathrm{mTorr}$, which is correlated to a reduction in structural defects, as evidenced by HRTEM for lower $\mathrm{N}_{2}$ pressures where a continuous film was achieved. The changes in nanorod morphology upon Ar-dilution of the $\mathrm{N}_{2}$ working gas are explained by a transition from $\mathrm{N}$-rich growth conditions which promote a diffusion induced NR growth mode, to Ga-rich growth conditions; this growth behavior is in agreement with previous qualitative data on GaN NR growth by MBE. All samples exhibited strong band edge emissions located at around $3.48 \mathrm{eV}$, containing $\mathrm{X}_{\mathrm{A}}$ and $\mathrm{D}^{0} \mathrm{XA}$. At $4 \mathrm{~K}$ PL. The peak located at $3.429 \mathrm{eV}$ is associated with SF emission, which was evidenced by HRTEM. At $P_{\mathrm{N} 2}$ $=2.5$ mTorr, the Ga-target is close to a non-poisoned state which gives the most perfect crystal quality, which is reflected in exceptionally narrow BE emissions at $3.479 \mathrm{eV}$ with a FWHM of only $1.7 \mathrm{meV}$ and negligible SF emission. Such structural and optical properties are comparable to rods previously grown at three to four times higher total working pressures of pure $\mathrm{N}_{2}$.

Acknowledgments: This work was supported by the Swedish Research Council (VR) under grants Nos. 621-2013-5360, 621-2012-4420, and 2016-04412. The authors further acknowledge the Swedish Foundation for Strategic Research (SSF) through the MS²E, and Nano-N programs and the Swedish Government Strategic Research Area Grant in Materials Science AFM-SFO MatLiU (grant 2009-00971). The support for the electron microscopy laboratory by the Knut and Alice Wallenberg Foundation is gratefully acknowledged.

Author Contributions: M.J., C.-L.H., Y.-T.C., and J.B. conceived and designed the experiments; M.J., C.-L.H., and Y.-T.C. performed the growth of GaN; M.J. and Y.-T.C., characterized optical properties of GaN nanorods; J.L. and J.P. performed TEM and analyzed the data together with P.O. A.P., L.H., and M.J.,C.L.-H. and J.B. analyzed XRD data; M.J. wrote the manuscript with revision by C.-L.H, Y.-T.C., L.H., and J.B. All authors agreed on the final version of the manuscript.

Conflicts of Interest: The authors declare no conflict of interest.

\section{References}

1. Luryi, S.; Xu, J.; Zaslavsky, A. Future Trends in Microelectronics; From Nanophotonics to Sensor and Energy; John Wiley \& Sons, Inc.: Hoboken, NJ, USA, 2010.

2. Lieber, C.M.; Wang, Z.L. Functional nanowires. MRS Bull. 2007, 32, 99-104. [CrossRef]

3. Huang, Y.; Duan, X.; Lieber, C.M. Nanowires for integrated multi color nanophotonics. Small 2005, 1, 142. [CrossRef] [PubMed]

4. Minot, E.D.; Kelkensberg, F.; van Kouwen, M.; van Dam, J.A.; Kouwenhoven, L.P.; Zwiller, V.; Borgström, M.T.; Wunnicke, O.; Verheijen, M.A.; Bakkers, E.P.A.M. Single quantum dot nanowire LEDs. Nano Lett. 2007, 7, 367-371. [CrossRef] [PubMed]

5. Lekhal, K.; André, Y.; Trassoudaine, A.; Gil, E.; Avit, G.; Cellier, J.; Castelluci, D. Exceptional crystal-defined bunched and hyperbunched GaN nanorods grown by catalyst-free HVPE. Cryst. Growth Des. 2012, 12, 2251-2256. [CrossRef]

6. Li, S.; Waag, A. GaN based nanorods for solid state lighting. J. Appl. Phys. 2012, 111, 071101. [CrossRef]

7. Ko, S.-M.; Kim, J.-H.; Ko, Y.-H.; Chang, Y.H.; Kim, Y.-H.; Yoon, J.; Lee, J.Y.; Cho, Y.-H. Growth mechanism of catalyst-free and mask-free heteroepitaxial GaN submicrometer- and micrometer-sized rods under biaxial strain: Variation of surface energy and adatom kinetics. Cryst. Growth Des. 2012, 12, 3838. [CrossRef]

8. Bertness, K.A.; Roshko, A.; Mansfield, L.M.; Harvey, T.E.; Sanford, N.A. Mechanism for spontaneous growth of GaN nanowires with molecular beam epitaxy. J. Cryst. Growth 2008, 310, 3154-3158. [CrossRef]

9. Calarco, R.; Meijers, R.J.; Debnath, R.K.; Stoica, T.; Sutter, E.; Lüth, H. Nucleation and growth of GaN nanowires on Si (111) performed by molecular beam epitaxy. Nano Lett. 2007, 7, 2248-2251. [CrossRef] [PubMed]

10. Landré, O.; Bougerol, C.; Renevier, H.; Daudin, B. Nucleation mechanism of GaN nanowires grown on (111) Si by molecular beam epitaxy. Nanotechnology 2009, 20, 415602. [CrossRef] [PubMed]

11. Tu, L.W.; Hsiao, C.L.; Chi, T.W.; Lo, I.; Hsieh, K.Y. Self-assembled vertical GaN nanorods grown by molecular-beam epitaxy. Appl. Phys. Lett. 2003, 82, 1601-1603. [CrossRef] 
12. Junaid, M.; Chen, Y.-T.; Palisaitis, J.; Garbrecht, M.; Hsiao, C.-L.; Persson, P.O.Å.; Hultman, L.; Birch, J. Liquid-target reactive magnetron sputter epitaxy of high quality GaN (0001-) nanorods on $\mathrm{Si}(111)$. Mater. Sci. Semicond. Proc. 2015, 39, 702-710. [CrossRef]

13. Serban, E.A.; Junaid, M.; Tengdelius, L.; Högberg, H.; Hultman, L.; Persson, P.O.Å.; Birch, J.; Hsiao, C.-L. Magnetron sputter epitaxy of single-crystal GaN nanorods on functional and cost-effective templates/substrates. Energies 2017, 10, 1322. [CrossRef]

14. Serban, E.A.; Palisaitis, J.; Yeh, C.-C.; Hsu, H.-C.; Tsai, Y.-L.; Kuo, H.-C.; Junaid, M.; Hultman, L.; Persson, P.O.Å.; Birch, J.-L.; et al. Selective-area growth of single-crystal wurtzite GaN nanorods on $\mathrm{SiO} x / \mathrm{Si}$ (001) substrates by magnetron sputter epitaxy exhibiting single-mode lasing. Sci. Rep. 2017, 7, 12701. [CrossRef] [PubMed]

15. Serban, E.A.; Palisaitis, J.; Persson, P.O.Å.; Hultman, L.; Birch, J.; Hsiao, C.-L. Site-controlled growth of GaN nanorod arrays by magnetron sputter epitaxy. Thin Solid Films 2018. In press. [CrossRef]

16. Junaid, M.; Hsiao, C.L.; Palisaitis, J.; Jensen, J.; Persson, P.O.Å.; Hultman, L.; Birch, J. Electronic-grade $\mathrm{GaN}(0001) / \mathrm{Al}_{2} \mathrm{O}_{3}(0001)$ grown by reactive dc-magnetron sputter epitaxy using a liquid Ga target. Appl. Phys. Lett. 2011, 98, 141915. [CrossRef]

17. Junaid, M.; Lundin, D.; Palisaitis, J.; Hsiao, C.-L.; Darakchieva, V.; Jensen, J.; Persson, P.O.Å.; Sandström, P.; Helmersson, U.; Hultman, L.; et al. Two-domain formation during the epitaxial growth of GaN (0001) on c-plane Al2O3 (0001) by high power impulse magnetron sputtering. J. Appl. Phys. 2011, 110, 123519. [CrossRef]

18. Greczynski, G.; Lu, J.; Jensen, J.; Petrov, I.; Greene, J.E.; Bolz, S.; Kölker, W.; Schiffers, C.; Lemmer, O.; Hultman, L. Metal vs. Rare-gas Ion Irradiation during Ti1 xAlxN Film Growth by Hybrid HIPIMS/DCMS Co-sputtering using Synchronized Pulsed Substrate Bias. J. Vac. Sci. Technol. A 2012, 30, 061504. [CrossRef]

19. Greczynski, G.; Petrov, I.; Greene, J.E.; Hultman, L. Strategy for tuning the average charge state of metal ions incident at the growing film during HIPIMS deposition. Vacuum 2015, 116, 36-41. [CrossRef]

20. Ivanov, I.; Kazansky, P.; Hultman, L.; Petrov, I.; Sundgren, J.-E. Influence of an external axial magnetic field on the plasma characteristics and deposition conditions during direct current planar magnetron sputtering. J. Vac. Sci. Technol. A 1994, 12, 314. [CrossRef]

21. Li, B.-S.; Wang, T.-G.; Ding, J.; Cai, Y.; Shi, J.; Zhang, X. Influence of $\mathrm{N}_{2}$ / Ar flow ratio on microstructure and properties of the $\mathrm{AlCrSiN}$ coatings deposited by high-power impulse magnetron sputtering. Coatings 2018, 8, 3. [CrossRef]

22. Amloy, S.; Chen, Y.T.; Karlsson, K.F.; Chen, K.H.; Hsu, H.C.; Hsiao, C.L.; Chen, L.C.; Holtz, P.O. Polarization resolved fine structure splitting of zero-dimensional InGaN excitons. Phys. Rev. B 2011, 83, 201307. [CrossRef]

23. Chen, Y.T.; Tsai, W.C.; Chen, W.Y.; Hsiao, C.L.; Hsu, H.C.; Chang, W.H.; Hsu, T.M.; Chen, K.H.; Chen, L.C. Growth of sparse arrays of narrow GaN nanorods hosting spectrally stable InGaN quantum disks. Opt. Express 2012, 20, 16166. [CrossRef]

24. Debnath, R.K.; Meijers, R.; Richter, T.; Stoica, T.; Calarco, R.; Lüth, H. Mechanism of molecular beam epitaxy growth of GaN nanowires on Si (111). Appl. Phys. Lett. 2007, 90, 123117. [CrossRef]

25. Bertness, K.A.; Sanford, N.A.; Davydov, A.V. GaN nanowires grown by molecular beam epitaxy. IEEE J. Sel. Top. Quantum Electron. 2011, 17, 847-858. [CrossRef]

26. Stoica, T.; Sutter, E.; Meijers, R.J.; Debnath, R.K.; Calarco, R.; Lüth, H.; Grützmacher, D. Interface and wetting layer effect on the catalyst-free nucleation and growth of GaN nanowires. Small 2008, 4, 751-754. [CrossRef] [PubMed]

27. Geelhaar, L.; Chèze, C.; Jenichen, B.; Brandt, O.; Pfüller, C.; Münch, S.; Rothemund, R.; Reitzenstein, S.; Forchel, A.; Kehagias, T.; et al. Properties of GaN Nanowires Grown by Molecular Beam Epitaxy. IEEE J. Sel. Top. Quantum Electron. 2011, 17, 878-888. [CrossRef]

28. Yoshizawa, M.; Kikuchi, A.; Mori, M.; Fujita, N.; Kishino, K. Growth of self-organized GaN nanostructures on $\mathrm{Al}_{2} \mathrm{O}_{3}$ (0001) by RF-radical source molecular beam epitaxy. Jpn. J. Appl. Phys. 1997, 36, L459-L462. [CrossRef]

29. Calleja, E.; Sánchez-García, M.A.; Sánchez, F.J.; Calle, F.; Naranjo, F.B.; Muñoz, E.; Jahn, U.; Ploog, K. Luminescence properties and defects in GaN nanocolumns grown by molecular beam epitaxy. Phys. Rev. B 2000, 62, 16826-16834. [CrossRef]

30. Consonni, V. Self-induced growth of GaN nanowires by molecular beam epitaxy: A critical review of the formation mechanisms. Phys. Status Solidi RRL 2013, 7, 699-712. [CrossRef] 
31. Foxon, C.T.; Novikov, S.V.; Hall, J.L.; Campion, R.P.; Cherns, D.; Griffiths, I.; Khongphetsak, S. A complementary geometric model for the growth of GaN nanocolumns prepared by plasma-assisted molecular beam epitaxy. J. Cryst. Growth 2009, 311, 3423-3427. [CrossRef]

32. Chèze, C.; Geelhaar, L.; Trampert, A.; Riechert, H. In situ investigation of self-induced GaN nanowire nucleation on Si. Appl. Phys. Lett. 2010, 97, 043101. [CrossRef]

33. Ababneh, A.; Schmid, U.; Hernando, J.; Sánchez-Rojas, J.L.; Seidel, H. The influence of sputter deposition parameters on piezoelectric and mechanical properties of AlN thin films. Mater. Sci. Eng. B 2010, 172, 253-258. [CrossRef]

34. Venkataraj, S.; Severin, D.; Drese, R.; Koerfer, F.; Wuttig, M. Structural, optical and mechanical properties of aluminium nitride films prepared by reactive DC magnetron sputtering. Thin Solid Films 2006, 502, 235-239. [CrossRef]

35. Zywietz, T.; Neugebauer, J.; Scheffler, M. Adatom diffusion at GaN (0001) and (0001-) surfaces. Appl. Phys. Lett. 1998, 73, 487-489. [CrossRef]

36. Paskov, P.P.; Paskova, T.; Holtz, P.O.; Monemar, B. Spin-exchange splitting of excitons in GaN. Phys. Rev. B 2001, 64, 115201. [CrossRef]

37. Paskov, P.P.; Schifano, R.; Paskova, T.; Figge, S.; Hommel, D.; Monemar, B. Emission properties of a -plane GaN grown by metal-organic chemical-vapor deposition. J. Appl. Phys. 2005, 98, 093519. [CrossRef]

38. Forsberg, M.; Serban, E.A.; Poenaru, I.; Hsiao, C.L.; Junaid, M.; Birch, J.; Pozina, G. Stacking fault related luminescence in GaN nanorods. Nanotechnology 2015, 26, 355203. [CrossRef] [PubMed]

39. Pozina, G.; Forsberg, M.; Serban, E.A.; Hsiao, C.-L.; Junaid, M.; Birch, J.; Kaliteevski, M.A. Polarization of stacking fault related luminescence in GaN nanorods. AIP Adv. 2017, 7, 015303. [CrossRef]

40. Ito, S.; Nakagita, T.; Sawaki, N.; Ahn, H.S.; Irie, M.; Hikosaka, T.; Honda, Y.; Yamaguchi, M.; Amano, H. Nature of yellow luminescence band in GaN grown on Si substrate. Jpn. J. Appl. Phys. 2014, 53, 11 RC02. [CrossRef]

41. Diaz-Guerra, C.; Piqueras, J. Time-resolved cathodoluminescence and photocurrent study of the yellow band in Si-doped GaN. J. Appl. Phys. 2003, 94, 2341-2343. [CrossRef]

42. Liu, B.; Yuan, F.; Dierre, B.; Sekiguchi, T.; Zhang, S.; Xu, Y.; Jiang, X. Origin of yellow-band emission in epitaxially grown GaN nanowire arrays. ACS Appl. Mater. Interfaces 2014, 6, 14159-14166. [CrossRef] [PubMed] 